\title{
Social dominance orientation predicts lower moral condemnation of causing harm to animals
}

\author{
Tomasz farmakowski-Kostrzanowski (D) $1 \cdot A, B, C, D, E, F$, Piotr Radkiewicz (1D) $2 \cdot A, B, D, E$ \\ 1: Institute of Psychology, Faculty of Philosophy and Social Sciences, Nicolaus Copernicus University, Toruń, Poland \\ 2: Institute of Psychology, Polish Academy of Sciences, Warsaw, Poland
}

\section{BACKGROUND}

Recent studies and theorizing (SD-HARM model) suggested that social dominance orientation (SDO) constitutes the ideological foundation of negative attitude towards animals and acceptance of their exploitation. At the same time, right-wing authoritarianism (RWA) is expected to predict speciesist beliefs only when they are perceived as part of societal tradition. The present studies investigated these predictions with moral condemnation of harm done to animals by humans as an indicator of speciesism.

\section{PARTICIPANTS AND PROCEDURE}

400 and 324 people, aged 18-87, took part in two crosssectional studies. They reported their levels of SDO and RWA and made moral judgments of harm done to animals.

\section{RESULTS}

In both studies, SDO, but not RWA, negatively predicted moral condemnation of harming animals.

\section{CONCLUSIONS}

The results offer additional support for the SD-HARM model. The more people accept SDO beliefs, the less they morally condemn harm done to animals by humans.

\section{KEY WORDS}

social dominance orientation; human-animal relations; animal exploitation; speciesism; moral judgment

CORResPonding Author - Tomasz Jarmakowski-Kostrzanowski, Ph.D., Institute of Psychology, Faculty of Philosophy and Social Sciences, Nicolaus Copernicus University, Fosa Staromiejska 1 A, 87-100 Toruń, Poland, e-mail: tjarmakowski@umk.pl

AUthors' CONTRIBUtion - A: Study design - B: Data collection - C: Statistical analysis - D: Data interpretation . E: Manuscript preparation · F: Literature search · G: Funds collection

TO CITE THIS ARTICLE - Jarmakowski-Kostrzanowski, T., \& Radkiewicz, P. (2021). Social dominance orientation predicts lower moral condemnation of causing harm to animals. Current Issues in Personality Psychology, 9(3), 229-236. RECEIVED 25.11.2020 · REVIEWED 09.02.2021 · ACCEPTED 22.03.2021 • PUBLISHED 03.05.2021 


\section{BACKGROUND}

The acceptance of systematic exploitation of animals by humans - often referred to as "speciesism" (Dhont et al., 2020) - has become an important social and political issue. Thus, it is not surprising that in the last decade, social psychologists have focused on psychological mechanisms and ideological foundations of differences in the way people perceive, value, and treat animals (e.g., Dhont \& Hodson, 2014; Dhont et al., 2016, 2020). Dhont and colleagues (2016) postulated that the individual variation in social dominance orientation constitutes the ideological roots of the acceptance of a speciesist attitude. This article presents the results of two studies that tested this general hypothesis with a specific indicator of speciesism moral judgment of harm done to animals.

\section{IDEOLOGICAL ROOTS OF SPECIESISM}

Dhont and colleagues (2016), based on the repeatedly observed correlations between prejudices against human outgroups and negative attitudes towards animals (Dhont et al., 2014; Hodson \& Dhont, 2015), postulated that negative attitudes towards other human groups and animals shared the same ideological roots. Following their approach, we can use the theoretical models developed to explain the ideological foundations of prejudice against human outgroups when looking for an explanation for negative attitude towards animals.

We believe that the dual-process motivational (DPM) model developed by Duckitt and Sibley (2010) is the most suitable for this purpose. The authors identified two distinct ideological foundations of prejudices against human outgroups. They were conceptualized as social dominance orientation (SDO) and right-wing authoritarianism (RWA). These two sets of beliefs and attitudes have different psychological and social bases. SDO is defined as a general acceptance of the existing hierarchical social systems and inequality between groups (Hudson et al., 2019). It stems from the belief that the social world is a ruthlessly competitive jungle, expresses selfenhancement values (achievement, power, and hedonism) and the motivation to dominate other low-status individuals/groups (Duckitt \& Sibley, 2010). RWA is defined as the covariation of conventionalism, authoritarian submission, and authoritarian aggression (Kessler \& Cohrs, 2008). It is rooted in perceiving the social world as dangerous and chaotic, based on a motivation to establish and maintain societal security, order, and stability in one's group and related to the conservation values (security, conformity, and tradition; Duckitt \& Sibley, 2010). Because SDO and RWA are based on different motivational goals and values, they were expected to have different effects on prejudice. Correlational and longitudinal studies (Asbrock et al., 2010; Duckitt \& Sibley, 2010) indicated that SDO, but not RWA, predicted the prejudice towards disadvantaged groups (e.g., "unemployed people”). In contrast, RWA, but not SDO, predicted a negative attitude to groups perceived as a threat to social order or ingroup norms/values (e.g., "people who disrupt safety and security in our society").

When we apply this model to the human-animal relationship, the very first thing we notice is that animals, in comparison to humans, have low status and are almost helpless and easy to exploit (Dhont et al., 2020). Since SDO was conceptualized as an expression of a desire to dominate and discriminate against low-status groups, we can expect that SDO will predict beliefs in human supremacy and acceptance of animal exploitation. In turn, RWA stems from motivation to maintain ingroup cohesion and stability that animals do not threaten. However, the actions or ideologies that oppose animal exploitation (e.g., animals' rights movements or vegetarianism/veganism) can be perceived as threats to ingroup tradition and identity. Based on these arguments, RWA was expected to be a predictor of acceptance of animal mistreatment and exploitation only when it was perceived as part of tradition or ingroup identity. These predictions, systematized as the Social Dominance Human-Animal Relations Model (SD-HARM; Dhont et al., 2016), have gained some empirical support. People high in SDO held greater human supremacy beliefs over animals, more often consumed meat, and had greater acceptance of animal exploitation (Bilewicz et al., 2011; Caviola et al., 2019; Dhont \& Hodson, 2014; Dhont et al., 2014, 2016). At the same time, RWA predicted the level of vegetarianism threat (perceiving vegetarianism as a threat to ingroup tradition and identity), but not human supremacy beliefs (Dhont \& Hodson, 2014). Furthermore, the relationship between RWA and animal exploitation acceptance was fully mediated by the vegetarianism threat (Dhont \& Hodson, 2014; Dhont et al., 2016).

\section{THE CURRENT STUDIES}

Studies supporting the SD-HARM model have usually been based on self-reported beliefs about what the human-animal relationship should look like (e.g., "Much of scientific research done with animals is unnecessary and cruel" or "I think it is perfectly acceptable for cattle, chickens, and pigs to be raised for human consumption" from Dhont et al., 2016). Nevertheless, the negative attitude towards animals manifests also in the way people treat animals and how they morally judge harming them (Dhont et al., 2020). In fact, Caviola and collaborators (2019, p. 2) defined speciesism as an "assignment of different inherent moral status based solely on an individual's species member- 
ship". To our knowledge, there is no study testing the SD-HARM model with speciesism measured with moral judgments of harm done to animals by humans. The studies presented here aimed to fill this gap.

Based on the SD-HARM model, we predicted that people high in SDO would express lower moral condemnation of harm done to animals by humans. At the same time, RWA, as a manifestation of a motivational goal to maintain ingroup norms and stability, should not be related to the level of moral condemnation of harming animals unless it relates to tradition or ingroup identity.

The previous studies (Caviola et al., 2019; Dhont et al., 2014, 2016) suggested that the SDO-speciesism relationship was between 0.4 and 0.5 (Pearson's coefficient $r$ ). We expected the relationship between ideological variable (SDO) and moral judgment to be weaker. Assuming the expected relationship between SDO and the moral condemnation of harming animals at the level 0.2 (Pearson's coefficient $r$ ), we set our minimum sample size at $n=259$ participants by power analysis.

\section{STUDY 1}

\section{PARTICIPANTS AND PROCEDURE}

Study 1 was conducted on a representative sample of 400 adult Poles (207 women). Their age ranged from 18 to 87 , with average $M_{\text {age }}=47.44\left(S D_{\text {age }}=15.90\right)$. The interviews were conducted in the respondents' homes by trained interviewers using a computerized questionnaire format ${ }^{1}$.

Respondents completed a 12-item SDO scale (Siadnius \& Pratto, 1999; e.g., "Some people are just more worthy than others") with a 6-point scale from 1 (strongly disagree) to 6 (strongly agree) and a shortened 7-item version of the RWA scale ${ }^{2}$ (Funke, 2005; e.g., "Obedience and respect for authority are the most important virtues children should learn") with a 7-point scale from 1 (strongly disagree) to 7 (strongly agree).

To measure the degree of moral condemnation of harm done to animals, we asked participants to rate the moral wrongness of behaviours described in four short scenarios. In all scenarios, animals are being harmed by humans. Responses for all moral vignettes were coded on a 5-point scale from 1 (not at all morally wrong) to 5 (extremely morally wrong). The full list of moral vignettes we used is provided in supplementary materials (Appendix B). The internal consistency measures (Cronbach's $\alpha$ ) for all scales are reported in Table 1.

\section{RESULTS AND DISCUSSION}

First, we analysed correlations between SDO, RWA, and moral condemnation (Table 1). As predicted, high level of SDO was related to lower moral condemnation of harm done to animals. However, contrary to our prediction, people high in RWA were slightly more prone to condemn harming animals.

Then we regressed the moral judgment of harming animals on SDO and RWA. The variance inflation factor (VIF) was 1.02. This suggests that multicollinearity was not a concern. As shown in Table 2, SDO predicts negatively and RWA positively the degree of moral condemnation of harming animals.

The results of study 1 provided initial support for the tested hypothesis. High SDO was associated with lesser moral condemnation of harming animals. However, the positive relation between RWA and moral condemnation of harming animals was an unexpected result. The limitation of this study was the way we measured the moral condemnation of animal harm. Our scale consisted of only four scenarios, so it might

\section{Table 1}

Descriptive statistics and correlations (studies 1 and 2)

\begin{tabular}{lcccccc}
\hline Variable & Study & $\alpha$ & $M$ & $S D$ & \multicolumn{2}{c}{ Pearson's coefficient $r$} \\
\cline { 5 - 7 } & & & & & 2 & 3 \\
\hline 1. SDO & $\mathrm{S} 1$ & .63 & 3.11 & 0.50 & $-.13(p=.008)$ & $-.22(p<.001)$ \\
& $\mathrm{S} 2$ & .77 & 2.89 & 0.64 & $.27(p<.001)$ & $-.29(p<.001)$ \\
2. RWA & $\mathrm{S} 1$ & .81 & 4.97 & 0.93 & $.17(p=.001)$ \\
& $\mathrm{S} 2$ & .81 & 3.79 & 0.91 & $-.06(p=.290)$ \\
3. Moral condemnation of harming & $\mathrm{S} 1$ & .68 & $4.29^{\mathrm{a}}$ & 0.64 & & \\
animals & $\mathrm{S} 2$ & .93 & $4.78^{\mathrm{a}}$ & 0.38 & & \\
\hline
\end{tabular}

Note. SDO - social dominance orientation; RWA - right-wing authoritarianism; ${ }^{a}$ the higher the value, the higher the moral condemnation of harm done to animals. 
Table 2

Regression of moral judgments of harm done to animals on SDO and RWA (studies 1 and 2)

\begin{tabular}{lcccccc}
\hline Predictors & Study & $b$ & SE & $\beta$ & $p$ & $95 \% \mathrm{Cl}$ \\
\hline Constant & S1 & 4.63 & .27 & & $<.001$ & {$[4.10 ; 5.17]$} \\
& S2 & 5.26 & .11 & & $<.001$ & {$[5.04 ; 5.49]$} \\
SDO & S1 & -0.26 & .06 & -.21 & $<.001$ & {$[-0.39 ;-0.14]$} \\
& S2 & -0.18 & .03 & -.30 & $<.001$ & {$[-0.24 ;-0.11]$} \\
RWA & S1 & 0.10 & .03 & .14 & .004 & {$[0.03 ; 0.16]$} \\
& S2 & 0.01 & .02 & .02 & .691 & {$[-0.04 ; 0.06]$} \\
$R^{2}$ (corrected) & S1 & & & & .07 & \\
\end{tabular}

Note. SDO - social dominance orientation; RWA - right-wing authoritarianism.

have captured only a few forms of harming animals. Thus, we conducted study 2 using an expanded, more valid measure of moral judgment of harming animals to replicate the findings from study 1.

\section{STUDY 2}

\section{PARTICIPANTS AND PROCEDURE}

We recruited 324 participants (191 women) from the online research panel (Ariadna), which has 80 thousand registered panel members. The participants' age ranged from 18 to 78 , with an average $M_{\text {age }}=42.42$ $\left(S D_{\text {age }}=14.82\right)$.

Social dominance orientation was measured with the same 12-item scale as in study 1 . To measure right-wing authoritarianism, we used a 12-item RWA scale by Funke (2005). This time we did not observe any problems with recoded items, so we stuck to a 12-item version of the scale.

We used 13 vignettes to measure moral condemnation of harm done to animals. Relative to study 1 , the scenarios described more forms of harming animals and involved more species (e.g., cows, pigs). Like study 1 , all scenarios depicted humans' harm to animals. Participants made the moral judgments of described behaviours in the same manner as in study 1 . The whole list of moral vignettes can be found in supplementary materials (Appendix B). The internal consistency measures (Cronbach's $\alpha$ ) for all scales are reported in Table 1.

\section{RESULTS AND DISCUSSION}

SDO was once again negatively correlated with the moral condemnation of harm done to animals, but RWA was not (Table 1). When we entered SDO and
RWA into the regression model with moral judgment as a dependent variable (VIF $=1.08)$, SDO remained a significant predictor of moral condemnation of harming animals, whereas RWA was still not related to the judgment of such acts (Table 2).

Generally, study 2 replicated the results of study 1 concerning the relationship between SDO and moral judgment of harming animals. SDO negatively predicted the moral condemnation of humans harming animals, even after entering RWA into the model. This time the association between RWA and moral acceptance of animal harming was, as predicted, statistically insignificant and close to zero. This suggests that the positive relation between RWA and moral condemnation observed in study 1 was a false positive.

\section{GENERAL DISCUSSION}

The results of the presented studies support our hypothesis derived from the SD-HARM model. Across two studies, social dominance orientation predicted the moral judgment of harm done to animals. The more an individual accepts beliefs conceptualized as SDO, the less she/he morally condemns harm done to animals by humans. In other words, the higher SDO is, the higher is the moral acceptance of harming animals. Such results are in line with the SD-HARM thesis that, as the expression of motivation to dominate other individuals or groups, SDO constitutes the ideological basis for generalized negative attitudes towards different low-status outgroups, including animals (Dhont et al., 2016, 2020). From this perspective, animal exploitation by humans is just a specific example of the human tendency to dominate and exploit weaker groups and individuals. On the other hand, the attitudinal cluster of conventionalism, submission, and authoritarian aggression, conceptualized as RWA, was not related to moral judgments 
about harming animals (study 2) or was even slightly positively associated with moral condemnation of such human behaviour (study 1). We expected such results because the scenarios we used depicted examples of harming animals that were not related to ingroup tradition or identity. And this is the condition under which RWA, as an expression of resistance to cultural change, leads to the acceptance of animal exploitation (Dhont \& Hodson, 2014; Dhont et al., 2020).

Why are people high in SDO more prone to morally accept harm done to animals? Our current study does not offer a direct answer to this question. Nevertheless, the literature on the nature of SDO and the human-animals relationship offers a reliable explanation. People high in SDO are motivated to maintain the existing hierarchy - animal exploitation by humans in this case. Thus, they tend to feel reduced empathy towards members of dominated outgroups in everyday situations (Hudson et al., 2019), which creates separation between social dominants and those who suffer under the current hierarchy (Nicol \& Rounding, 2013) and facilitates hierarchy maintenance. Moral concern and moral judgments of harming others are largely based on empathy and compassion towards the victims (e.g., Graham et al., 2013; Haidt, 2003). We believe that reduced empathy towards animals enables social dominators to maintain human dominance and exploitation and results in lower moral condemnation of harming animals.

This research's apparent limitation is its correlational design, which does not allow for direct inference of a causal relationship between the ideological beliefs and the moral judgments of harming animals. A longitudinal research design could provide a more straightforward answer regarding causal directions among the discussed constructs. Likewise, it would be beneficial to test whether SDO predicts lower emphatic reactions to animal suffering as we observed it for the suffering of human outgroups' members (Hudson et al., 2019).

In conclusion, our results present another argument in support of the SD-HARM model. SDO, but not RWA, predicts moral tolerance to harming animals. This suggests that social dominance orientation constitutes an ideological and moral foundation for dominating and exploiting members of outgroups, both humans and animals.

\section{ENDNOTES}

1 In line with the Center for Open Science's recommendations for a more transparent science, we state that the measures reported here (both studies 1 and 2) are not the only variables measured in the database. The full list of measures can be found in supplementary materials (Appendix A).
2 We used a 12-item version of the RWA scale proposed by Funke. However, during the analysis, we found out that all five recoded items drastically reduced Cronbach's $\alpha$. Faced with such a problem, we decided to rely only on the remaining seven items (not recoded ones).

\section{REFERENCES}

Asbrock, F., Sibley, C. G., \& Duckitt, J. (2010). Rightwing authoritarianism and social dominance orientation and the dimensions of generalized prejudice: a longitudinal test: Dimensions of generalized prejudice. European Journal of Personality, 24, 324-340. https://doi.org/10.1002/per.746

Bilewicz, M., Imhoff, R., \& Drogosz, M. (2011). The humanity of what we eat: Conceptions of human uniqueness among vegetarians and omnivores. European Journal of Social Psychology, 41, 201-209. https://doi.org/10.1002/ejsp.766

Caviola, L., Everett, J. A. C., \& Faber, N. S. (2019). The moral standing of animals: Towards a psychology of speciesism. Journal of Personality and Social Psychology, 116, 1011-1029. https://doi.org/ 10.1037/pspp0000182

Dhont, K., \& Hodson, G. (2014). Why do right-wing adherents engage in more animal exploitation and meat consumption? Personality and Individual Differences, 64, 12-17. https://doi.org/10.1016/j. paid.2014.02.002

Dhont, K., Hodson, G., Costello, K., \& MacInnis, C. C. (2014). Social dominance orientation connects prejudicial human-human and human-animal relations. Personality and Individual Differences, 61-62, 105-108. https://doi.org/10.1016/j.paid.2013.12.020

Dhont, K., Hodson, G., \& Leite, A. C. (2016). Common ideological roots of speciesism and generalized ethnic prejudice: The Social Dominance HumanAnimal Relations Model (SD-HARM). European Journal of Personality, 30, 507-522. https://doi. org/10.1002/per.2069

Dhont, K., Hodson, K., Leite, A. C., \& Salmen, A. (2020). The psychology of speciesism. In K. Dhont \& G. Hodson (Eds.), Why we love and exploit animals: Bridging insights from academia and advocacy. Routledge.

Duckitt, J., \& Sibley, C. G. (2010). Personality, ideology, prejudice, and politics: a dual-process motivational model. Journal of Personality, 78, 1861-1894. https://doi.org/10.1111/j.1467-6494.2010.00672.x

Funke, F. (2005). The dimensionality of right-wing authoritarianism: Lessons from the dilemma between theory and measurement. Political Psychology, 26, 195-218. https://doi.org/10.1111/j.14679221.2005.00415.x

Graham, J., Haidt, J., Koleva, S., Motyl, M., Iyer, R., Wojcik, S. P., \& Ditto, P. H. (2013). Moral foun- 
dations theory: The pragmatic validity of moral pluralism. Advances in Experimental Social Psychology, 47, 55-130. https://doi.org/10.1016/B9780-12-407236-7.00002-4

Haidt, J. (2003). The moral emotions. In R. J. Davidson, K. R. Scherer, \& H. H. Goldsmith (Eds.), Handbook of affective sciences (pp. 852-870). Oxford University Press.

Hodson, G., \& Dhont, K. (2015). The person-based nature of prejudice: Individual difference predictors of intergroup negativity. European Review of Social Psychology, 26, 1-42. https://doi.org/10.1080/ 10463283.2015.1070018

Hudson, S. T. J., Cikara, M., \& Sidanius, J. (2019). Preference for hierarchy is associated with reduced empathy and increased counter-empathy towards others, especially outgroup targets. Journal of Experimental Social Psychology, 85, 103871. https://doi.org/10.1016/j.jesp.2019.103871

Kessler, T., \& Cohrs, J. C. (2008). The evolution of authoritarian processes: Fostering cooperation in large-scale groups. Group Dynamics: Theory, Research, and Practice, 12, 73-84. https://doi.org/10. 1037/1089-2699.12.1.73

Nicol, A. A. M., \& Rounding, K. (2013). Alienation and empathy as mediators of the relation between social dominance orientation, right-wing authoritarianism and expressions of racism and sexism. Personality and Individual Differences, 55, 294-299. https://doi.org/10.1016/j.paid.2013.03.009

Sidanius, J., \& Pratto, F. (1999). Social dominance: an intergroup theory of social hierarchy and oppression. Cambridge University Press. 
SUPPLEMENTARY MATERIALS

Appendix A

Other measures used in study 1 and study 2

Study 1

1. Moral Foundations Questionnaire (MFQ)

2. Portrait Values Questionnaire (PVQ)

3. Social Darwinism

4. Dangerous world belief

5. Communitarian and liberal orientation

6. Nationalism

7. Identification with the national group

8. Religious fundamentalism

9. Moral vignettes concerning five moral foundations postulated by moral foundation theory (concerning humans)

10. Beliefs about individual freedom

11. Immigrants threat

12. Social and economic conservatism

13. Sense of control

Study 2

1. Moral Foundations Questionnaire (MFQ)

2. Portrait Values Questionnaire (PVQ) - Universalism subscale

3. Moral vignettes concerning five moral foundations postulated by moral foundation theory (concerning humans)

4. Social and economic conservatism

5. Beliefs about public help distribution 


\section{Appendix B}

Moral vignettes

Study 1

1. A man keeps his dog on a very short chain (1 meter) in a non-insulated kennel for two years.

2. A dog's owners leave it tied to the railing of the stairs on a cold, rainy day, and they go out for a two-hour dinner.

3. A man goes hunting for animals every week.

4. The owner of a horse makes it jump with a whip to show off in front of his friends.

\section{Study 2}

1. A man keeps his dog on a very short chain (1 meter) in a non-insulated kennel for two years.

2. A dog's owners leave it tied to the railing of the stairs on a cold, rainy day, and they go out for a two-hour dinner.

3. A horse owner makes it jump with a whip to show off in front of his friends.

4. A group of teenagers is throwing rocks at a homeless dog for fun.

5. A man is kicking a cat because it has scratched the furniture with its claws.

6. A circus owner makes sick horses perform

7. A man keeps horses and cows in a barn in harsh conditions. The animals are kept in very narrow stalls. They are dirty, malnourished, and sick.

8. A man abandons his dog in the forest - tied to a tree.

9. A farmer goes on vacation, leaving his pigs hungry. The animals are not fed for many days.

10. A man hits a cow with all his might because it gave very little milk.

11. A man tied a cow to a tree with a chain so short that the animal could not even change position it had to remain motionless all the time.

12. A man got on his horse and tried to make it run, even though the horse was limping.

13. A mother allows her child to pull their dog by the ears even though the animal is yelping. 